\title{
A QUESTÃO DO SUJEITO EM MICHEL FOUCAULT
}

\section{Jeancarlo Pontes Carvalho ${ }^{1}$}

Resenha de: Michel Foucault e a Constituição do Sujeito: O cuidado de si e a constituição do Sujeito de Michel Foucault Mário Alves da Fonseca EDUC. Editora da PUC-SP São Paulo, 2016, 144 p.

A obra Michel Foucault e a Constituição do Sujeito (2016), de Márcio Alves da Fonseca recoloca a questão da periodização dos escritos de Foucault, elegendo como tema norteador da investigação o problema da historicidade e das experiências do sujeito, considerando-o a partir da constituição do indivíduo consciente de si na cultura Ocidental. Concentrando-se principalmente nos escritos genealógicos, o autor retoma os temas do poder disciplinar, do dispositivo da sexualidade, do controle das técnicas e do propósito de construir uma sociedade emergente capitalista industrial, com indivíduos dóceis, úteis e adaptáveis aos aparelhos de produção. Deste modo, após a apresentação dos argumentos desenvolvidos na sequência dos capítulos, passaremos para a análise da referida obra.

No Capítulo 1, Fonseca argumenta que o tema do sujeito é pertinente ao pensamento foucaultiano, buscando compreender, a partir do discurso, os processos de subjetivação e de objetivação. Ao longo da trajetória filosófica de Michel Foucault, tal temática aparece de modo constante e inquietante, ao ponto de não ser considerado apenas um dado, mas sim como algo constitutivo.

No Capítulo 2, argumenta que o sujeito e o poder são as principais inquietações que direcionam as obras da genealogia foucaultiana e é nesta encruzilhada que o tema da constituição do sujeito se situa, determinando o lugar bem como a importância em relação às noções que a temática sobre o sujeito se empreenderá.

No Capítulo 3, argumenta sobre a caracterização do poder disciplinar e a sua participação na constituição do sujeito, que implica seriamente na análise dos mecanismos de disciplinas e das formas segundo as quais se estabelecem as relações de poder existentes, especialmente voltadas para a formação do indivíduo moderno.

No Capítulo 4, argumenta que o indivíduo moderno pode ser descrito como um "indivíduo individual", ou seja, perpassado pelas estratégias disciplinares que o transformam em objeto "dócil-e-útil", marcado, assim, por sua constituição enquanto sujeito.

E, finalmente, no Capítulo 5, argumenta que a visão estabelecida pela análise de Foucault caracteriza a constituição e discute o seu significado, destrinchando, retrospectivamente,

\footnotetext{
${ }^{1}$ Graduado em Licenciatura em História pela UEMA, Pós-graduado em Patrimônio Cultural e Educação Patrimonial pela FIBRA, Licenciando em Filosofia pela Universidade do Estado do Amapá e Pós-graduando em Estudos Culturais e Políticas Públicas pela UNIFAP. E-mail: jeancarlop@,msn.com. Orcid: http://orcid.org/0000-0001-7358-0235
} 
outras formas de constituição do sujeito diferentes das da atualidade. A constituição do sujeito na Antiguidade estava associada à ética, isto é, à relação do sujeito consigo mesmo, sendo esta uma noção-chave para a compreensão das obras foucaultianas.

Apresentados brevemente os argumentos desenvolvidos por Fonseca (2016), passaremos agora para a análise sua obra.

\section{O SUJEITO COMO EIXO DA ANÁLISE}

O tema do sujeito perpassa o pensamento foucaultiano, bem como está presente na obra Michel Foucault e a Constituição do Sujeito a partir do problema da constituição dos discursos capazes de provocar os processos de subjetivação e de objetivação. Deste modo, o próprio ser humano que se engaja na tarefa de tornar-se um sujeito legítimo e determinado provoca a reflexão sobre o presente histórico de seu tempo.

Fonseca, neste sentido, expõe o problema da constituição do sujeito, enfatizando sua complexidade inerente, considerando as práticas constituídas nos âmbitos em que as noções do próprio sujeito perpassam os dispositivos, as estratégias e os mecanismos disciplinares, temas estes privilegiados no que diz respeito às reflexões metodológicas de Foucault, uma vez que este autor se refere às práticas judiciárias e à sexualidade.

Assim, o sujeito se torna uma das preocupações que acompanhou Foucault em toda a trajetória filosófica, demarcando um tipo específico de sujeito que está em constituição, indicando, mesmo que de forma velada, a necessidade constante de fazer escolhas. Oportuniza acesso direto aos objetos introduzindo as noções que permitem partir do âmbito da genealogia das obras às práticas estáveis em que os sujeitos aparecem despenhando papel nas relações conflituosas ou harmônicas.

Portanto, encontramos o caminho para compreender o lugar que o sujeito nas relações de poder, de força, nas estratégias políticas, bem como no campo da ética, levando em consideração o tempo e as relações disciplinares que entram em jogo no indivíduo moderno, nega, portanto, a ideia de um sujeito possuidor de uma essência trans-histórica e transcultural.

\section{O SUJEITO E O PODER}

A partir do eixo de análise que interpreta a obra de Foucault como especialmente dedicada ao sujeito, e não ao poder, parte-se da consideração sobre os trabalhos publicados durante os anos 1960 e 1980, configurando uma tentativa de produzir diferentes modos de subjetivação do ser humano, tornando possível afirmar que o ser humano se desenvolve em cada cultura, sendo este o fio condutor que adquiriu formas variadas que seriam privilegiadas a depender da obra considerada no que concerne ao sujeito falante, produtivo e vivente.

Neste sentido, Fonseca declara que Foucault representa um testemunho da própria obra, demonstrando de maneira especial as dificuldades de se estabelecer um elemento que não pode ser caracterizada nem como unidade imediata e nem como unidade certa. Afinal, segundo o autor, não haveria um conflito entre a reflexão metodológica de Foucault e a tendência de especificar aquilo que seria o problema central das suas obras.

Para tanto, Foucault critica a incapacidade daqueles que são detentores do discurso, ou seja, o próprio ser humano, que é capaz de ler as obras indicando uma preocupação para com os modos de subjetivação do homem. Assim como sobre a possibilidade de analisar os vários 
modos de objetivação do indivíduo enquanto produto de práticas discursivas e não discursivas, o que garante a Foucault uma autonomia de escolha dos objetos e dos métodos apropriados para a investigação, agrupando-os ou classificando-os em torno de um tema único.

Neste particular, a constituição de um sujeito moderno se justifica a partir da legitimidade do poder, que Foucault compara com o ordenamento jurídico, estabelecendo uma analogia que torna o fenômeno passível de ser explicado por um processo de racionalidade específica e global, criando uma teorização geral do poder a partir do significado de Estado.

Contudo, alguns aspectos são importantes para entendermos melhor as relações de força entre a sociedade e o Estado ${ }^{2}$. Assim, é preciso analisar o poder a partir dos mecanismos infinitesimais, ou seja, considerando que há um limite para a atuação dos aparelhos do Estado no que tange a história, as técnicas e as táticas, cabendo examinar como esses mecanismos de poder foram e ainda são investidos, ou seja, como as relações de poder podem ser utilizadas para colonizar, subjugar, transformar, entre outros.

\section{A disciplina como estratégia política}

Na descrição da prisão, dos suplícios corporais que ocorrem ao longo dos séculos XVII e XVIII, é possível determinar os mecanismos punitivos ${ }^{3}$. O produto extraído e percebido são as reações de gritos desesperados de dor e ou dos pedidos de perdão dos punidos, reconfigurando as relações de poder, demonstrando a importância da prisão naquele período, uma vez que houve “(...) uma evolução daquilo que chamará economia de poder. Novas formas de exercício de poder suscitariam mecanismos de punição” (FONSECA, 2016, p. 42).

O percurso realizado por Foucault em Vigiar e Punirt mostra a sua interpretação, que revela o aparecimento da prisão que perpassa por etapas "que se designa por punição generalizada, resultantes das Reformas Humanistas (...) momento de passagem da aplicação das punições generalizadas para o aprisionamento como revelador da formação de um novo tipo de exercício de poder, possuidor de novas exigências e necessidade" (FONSECA, 2016, p. 43).

Para tanto, o importante passo para obtermos o entendimento desta nova forma de poder é mostrar a vinculação ao tipo de exercício em que o poder se apresenta. Durante os séculos XVII e XVIII, os suplícios eram penas impostas aos criminosos de acordo com a gravidade do crime, podendo ser considerados como parte essencial de um ritual político, no qual se constitui a manifestação concreta do poder. Sendo assim, uma estratégia segundo a qual o poder se manifesta empregando-o ao povo como elemento essencial, como mecanismo que precisa sempre ser manifestado para que a população perceba o sentido que produz que vai desde o medo até o ponto de ser atraído pelo espetáculo do suplício.

A partir destas angústias, sobre as atrocidades cometidas pelo poder real, surge uma mudança na mentalidade da sociedade promovendo reformas no século XVIII, o que delineou a validade do suplício e justificou uma forma de poder que agora se apresenta por meio de um contrato social, e que se torna como a base da ideia de uma sociedade que faz com que qualquer violação, seja agora entendida como algo que deva ser condicionado por meio de uma reforma do direito criminal e a partir de então, punida por diversas esferas da sociedade, não sendo mais somente do poder real, como antes do século XVIII era realizado.

\footnotetext{
${ }^{2}$ FOUCAULT, M. Microfísica do poder. Organização, introdução e revisão técnica de Roberto Machado. 7 ed. Rio de Janeiro: Graal, 1988a.

3 FOUCAULT, M. "Sobre a prisão" (com J-J. Brochier). Tradução Marcelo Marques Damião. In: FOUCUALT, M. Microfísica do poder. 7 ed. Rio de Janeiro: Graal, 1988d.

${ }^{4}$ FOUCAULT, M. Vigiar e punir. Tradução de Lígia M. Ponde Vassalo. 6. Ed. Petrópolis: Vozes, 1988c.
} 
Assim, com esta mudança, estabelece-se uma nova concepção política que abrange a todos em um quadro segundo o qual qualquer ato atribuído ao soberano não se justificaria como crime e que o crime que receba castigo proporcional em relação ao dano, ou seja, que a punição ao criminoso aconteceria sem a intermediação do "poder de punir".

\section{O INDIVÍDUO MODERNO}

No século XVIII, Immanuel Kant inaugura uma nova maneira de pensar, marcando uma questão que, segundo Foucault, levaria à pergunta sobre o que seria o significado histórico e cultural da Revolução Francesa, vinculando este sentido de revolução ao processo mais amplo de "esclarecimento". Neste sentido, Kant elucida o sentido de esclarecimento (Aufklärung), que corresponde ao entendimento de saída do homem de sua menoridade, da qual ele próprio é culpado das ações.

Considerando que a menoridade seria a incapacidade de fazer uso de seu entendimento sem a direção de outro indivíduo, transporta-se para o homem a culpa por sua própria menoridade, quer dizer, se torna a causa dela, ou seja, o homem não se encontra na falta de entendimento, na falta de uma decisão e de decisão corajosamente dirigida para servir-se de si mesmo. Nisto temos a questão do esclarecimento que se tornou um fator essencial para a percepção do indivíduo, que, a partir de então, é considerado como sujeito moderno, constituído como capital, na medida em que há o investimento que visa estabelecer a justiça.

$\mathrm{Na}$ medida em que o sujeito torna-se capital, a prisão passa a operar segundo a lógica da punição e também como mecanismo disciplinar para o controle da criminalidade, sendo, portanto, peça relevante para a constituição da individualidade moderna dócil e útil. Isto posto, o biopoder representa uma transformação fundamental para implementação dos mecanismos do poder vinculada não apenas ao indivíduo, mas à vida das populações.

Assim, o controle dirige-se à vida do indivíduo, sendo este o sentido da obra Vigiar e Punir, que apresenta as estratégias disciplinares, que tornam o indivíduo um objeto, que sofre sobre o seu corpo vivo uma anátomo-política, considerado a disposição em $A$ vontade de saber ${ }^{5}$. Assim, os processos biológicos estão voltados para a reprodução, para as técnicas disciplinares aplicadas à constituição do indivíduo moderno.

\section{A CONSTITUIÇÃo ÉTICA dO SUJEITO NA ANTIGUIDADE}

Graças ao rompimento com a tradição que Foucault se considera “(...) capaz de se libertar de seu próprio pensamento continuando fiel a si mesmo” (FONSECA, 2016, p. 97), recolocando temas centrais sobre o sujeito apoiando-se na ética relacionado-a a reflexão sobre si. Deste modo ampliando a revelação de novas luzes sobre processos de subjetivação diversos das formas próprias da atualidade.

No pensamento antigo, ligado ao paganismo as relações de austeridade, das condutas ligadas às interdições e à moral estão ao âmbito social e civil e, neste sentido, legadas às escolhas privadas, nas quais a coerção não se aplicava. Entretanto, a austeridade moral criou espaços independentes das prescrições codificadas.

A moral apresentava-se nos códigos e a relação consigo mesmo na ética, nos atos, no comportamento de pessoas, portanto, uma genealogia entendida como constituição do sujeito

${ }^{5}$ FOUCAULT, M. A vontade de saber, 1985, p.26 / Foucault, M., La Volonté de savoir, 1976, p. 33. 
moral, que resulta nos aspectos primordiais da relação consigo mesmo, que determina o sujeito, integrando-o à conduta moral.

No que concerne à questão histórica do sujeito, a ética na Antiguidade, mais precisamente vigente no século IV a.C., temos o "uso dos prazeres" que estuda como foi este processo de subjetivação, partindo da identificação das formas da história dos códigos morais e da forma como foi formulada a questão da austeridade, de um modo geral, é possível identificar uma intensificação da austeridade nos mesmos núcleos de problematização que concernem à moral.

Entre eles temos o ato do sexo, considerado como uma forma de prazer, mas que apresenta consequências além da ação. Ou seja, o sexo é um elemento crucial para o entendimento do conceito do poder nas relações sociais.

Tal relação de poder é assinalada Foucault como sendo uma relação constitutiva do problema moral, já que as relações entre o homem e a mulher, mesmo no período grego, era vertical, na medida em que apenas ao homem cabia o status de homem livre, não lhe cabendo a obrigação de fidelidade conjugal, não havendo espaço para condutas no que diz respeito à questão moral, mesmo que, para ele, mantenha-se a obrigação de permanecer como chefe e o dever de autoridade enquanto administrador da casa.

\section{REFLEXÕES FINAIS}

O leitor encontra na obra Michel Foucault e a Constituição do Sujeito uma reflexão que evoca a "responsabilidade de nossas particularidades" (FONSECA, 2016, p. 133), especialmente voltada para a construção de uma ética capaz de exprimir uma forma distinta da constituição de si.

Para tanto, Fonseca destaca o conjunto das preocupações que inquietaram o Foucault, e, neste sentido, considera a centralidade da constituição do sujeito moderno, priorizando, portanto, os argumentos que conferiram as características a partir da análise genealógica, a partir da qual vincula a ideia de desconstruir e, principalmente, compreender o caminho percorrendo-o até chegar à ideia de uma constituição ética de si.

Nesta perspectiva, a abordagem da sociedade disciplinar é descrita pelos mecanismos disciplinares que se tornam, portanto, instrumentos de vigilância hierárquica, que se realiza por meio da sanção normalizadora e do exame. A partir deste ponto de vista apresentam-se as funções de distribuição espacial, que proporciona o controle das atividades, a organização das gêneses e a composição das forças.

A grande questão que Fonseca até então salienta é que esta individualidade não se esgota, pois, para Foucault, o problema é muito mais profundo. Uma vez que a constituição do sujeito está em questão não bastaria identificá-lo, devendo-se igualmente analisá-lo. Mas, acima de tudo, é necessário salientar a questão ética, pois esta remissão à cultura própria da Antiguidade Clássica, voltado ao sujeito moral a partir das práticas de si, levanta a inquietação sobre a condição contemporânea do sujeito moderna.

Este olhar voltado para os gregos envolve o homem moderno. Uma vez que isso se torna uma necessidade, Foucault aponta para a necessidade de cada homem e mulher definir-se como sujeito. Debatendo a relação que o homem moderno proporciona a partir do modelo de constituição desvinculado daquilo que o produz enquanto sujeito, referindo-se ao modo de constituição do poder normalizador. 
Desta maneira, a construção dessa ética, ou melhor, das trajetórias percorridas até se chegar à ética moderna, é uma tarefa proposta por Foucault, que problematiza a constituição do sujeito, apresentando a necessidade de reconsideração de inúmeros processos atuais, a fim de elencar formas de constituição de si por meio de uma ética que se elabora tanto no sujeito, quanto se projeta na constituição da moral.

\section{REFERÊNCIAS}

FOUCUALT, M. Microfísica do poder. Organização, introdução e revisão técnica de Roberto Machado. 7 ed. Rio de Janeiro: Graal, 1988a.

Doença mental e psicologia. Tradução de Lilian Rose Shalders. Rio de Janeiro:

Tempo Brasileiro, 1988b.

. Vigiar e punir. Tradução de Lígia M. Ponde Vassalo. 6. Ed. Petrópolis: Vozes, 1988c. "Sobre a prisão" (com J-J. Brochier). Tradução Marcelo Marques Damião. In: FOU-

CUALT, M. Microfísica do poder. 7 ed. Rio de Janeiro: Graal, 1988d.

A vontade de saber, 1985, p.26 / Foucault, M., La Volonté de savoir, 1976, p. 33. 